\title{
Modeling coal dust dispersion from pile with protection barriers
}

\author{
Mykola Biliaiev ${ }^{1, *}$, Viktoriia Biliaieva ${ }^{2}$, Oleksandr Berlov ${ }^{3}$, Vitalii Kozachyna ${ }^{1}$, \\ Pavlo Kirichenko ${ }^{4}$, Oladipo Mutiu Olatoye ${ }^{5}$, and Viktoriia Poltoratska ${ }^{3}$ \\ ${ }^{1}$ Dnipro National University of Railway Transport named after academician V. Lazaryan, 49010, \\ Dnipro, Lazaryan Str., 2, Ukraine \\ ${ }^{2}$ Oles Honchar Dnipro National University, 49010, Dnipro, Haharin Ave., 72, Ukraine \\ ${ }^{3}$ Prydniprovska state academy of civil engineering and architecture 49600, Dnipro, Chernyshevsky \\ Str., 24a, Ukraine \\ ${ }^{4}$ Kryvyi Rih National University, 50027, Kryvyi Rih, V. Matusevych Str., 11, Ukraine \\ ${ }^{5}$ GeoLab Drilling, 30680, Winder, Bill Rutledge Road, 800, GA USA
}

\begin{abstract}
The results of laboratory studies to evaluate the effectiveness of barriers which are used to reduce dust pollution from the coal pile are presented. The use of the $\Gamma$-shaped barrier, which is set differently near the coal pile model, has been studied. A numerical model is proposed to compute coal dust concentration in the air near the pile. The Navier-Stokes equations are used to model the wind flow over the coal pile. These equations are written in the variables "vorticity-stream function". To simulate the process of coal dust dispersion from the coal pile, the equation of convective-diffusion transfer of the passive impurity is used. For numerical integration of the modeling equations, difference schemes of splitting are used. Developed numerical model allows to perform numerical experiments taking into account the complex geometric shape of the pile and screens. The results of the computational experiments are presented.
\end{abstract}

\section{Introduction}

The coal industry has a negative impact on environmental pollution [9]. Intensive atmosphere pollution takes place during coal transportation or storing coal in piles $[1,2,8$, 9]. To reduce the intensity of environment pollution from coal piles, different methods are used (application of special solutions, watering, etc.). One of the most effective methods of reducing atmosphere pollution near coal piles is application of protection barriers. These protection barriers are located near the coal pile $[7,10,11]$. These barriers are nonexpensive and it does not take much time to install them near the coal pile. But application of such barriers requires scientific justification of their height, location relatively to the coal pile. It is also important to know the impact of barrier shape on the effectiveness of environmental protection. Laboratory and field study or computer simulation can be used to

\footnotetext{
*Corresponding author: diit.hydro.eco@gmail.com
} 
solve this problem. Using physical experiments takes considerable time to conduct research. The computer simulation of coal dust dispersion from piles requires application of CFD models, since in order to obtain justified data of dust contamination zones near the pile. Here, the most problem, is to simulate correctly wind flow over the coal pile having complex geometrical form. Such an aerodynamic problem can be solved only by CFD models $[10,11]$. In practice, to assess the level of air pollution from piles, etc. often the Gaussian model is used [8]. This model allows to calculate quickly the intensity and size of contamination zones, but it does not take into account the geometric shape of the coal pile, and the ability to use different protective measures. In this regard, this model can be used for "pilot" calculations. An analysis of scientific publications has shown that there is a shortage of CFD models in Ukraine that could be used to evaluate the efficiency of barriers to reduce dust pollution from coal piles.

The purpose of the work is experimental and theoretical studies of the efficiency of using barriers having complex shape to reduce environment pollution from the coal pile.

\section{Methods}

Laboratory study has been performed at the Laboratory of Environment Protection (Department of Hydraulics and Water Supply, Dnipro National University of Railway Transport). Study has been performed in according with the scientific program № $0115 \mathrm{U} 007226$ "Models and methods to assess risk and environment pollution caused by emission of hazard substances during accidents or organized outbursts".

Figure 1 shows sketch of the laboratory setup. We used coal from Mezhdyrichenskyi Enrichment Factory.

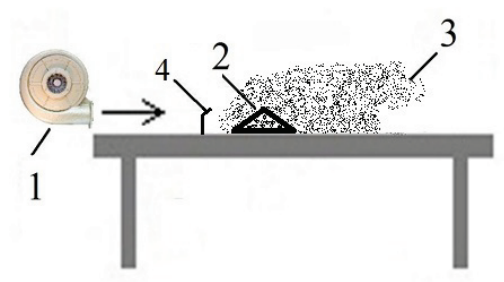

Fig. 1. Sketch of the laboratory setup: 1 - fan; 2 -model of the coal pile; 3 - contamination zone; 4 - barrier.

The model of the coal pile has a cone form (Figure 2). Diameter of this cone is $25 \mathrm{~cm}$ and the height of the cone is $10 \mathrm{~cm}$. During the experiments Reynold's number is $\operatorname{Re} \approx 10^{4}-10^{5}$, air temperature is $22^{\circ} \mathrm{C}$.

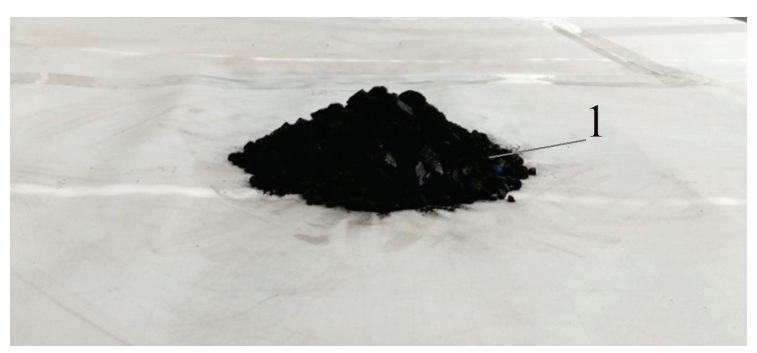

Fig. 2. Model of the coal pile: 1 - pile (scenario \# 1).

As the characteristic length $L$, to calculate Re number, the diameter of the cone has been chosen. To measure coal dust concentration Air Quality Detector WP6910 has been used. Wind speed has been measured with anemometer GM 8908. 
Figure 3 shows contamination zone which has been formed near the pile without protection barrier.

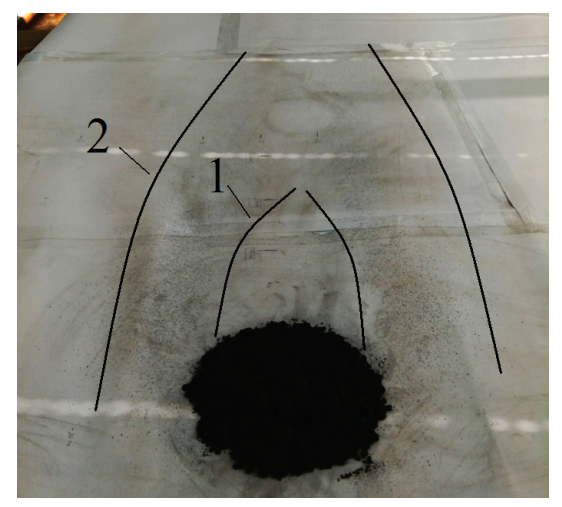

Fig. 3. Contamination zone near the model of the coal pile: 1 - zone of small contamination; 2 - zone of intensive contamination.

One can see from Figure 3 that contamination zone on the ground, near the coal pile, can be divided into two subregions. The first subregion has been formed behind the pile and it is light colored. It means that there is no intensive coal dust contamination in this subregion. This is explained by the fact that the pile itself plays the role of obstacle which makes "shadow" zones. As a result, at the leeward side of the pile the wind local speed is small and the coal dust emission rate, at this side, is small too.

The second subregion is formed as the "belt" which covers the first subregion. This sudregion has dark color, i.e. there is an intensive contamination. The width of the whole contamination zone is about $3 L$.

Barriers, which were used in laboratory experiments, are shown in Figures 4, 5. Two models of barriers have been used. The first model is barrier with " $\Gamma$ " form and its inclined part was directed to the pile (Figure 4). The second model has " $\Gamma$ " form but its inclined part is directed to wind (Figure 5). Wind direction is shown by "arrows" in Figures 4, 5.

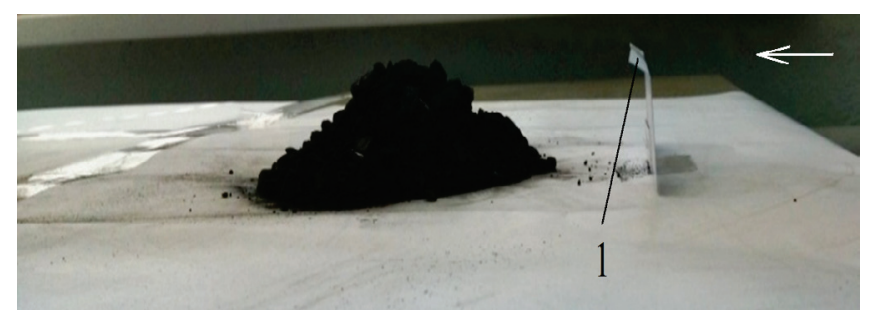

Fig. 4. Coal pile model: 1 - barrier (scenario \# 2).

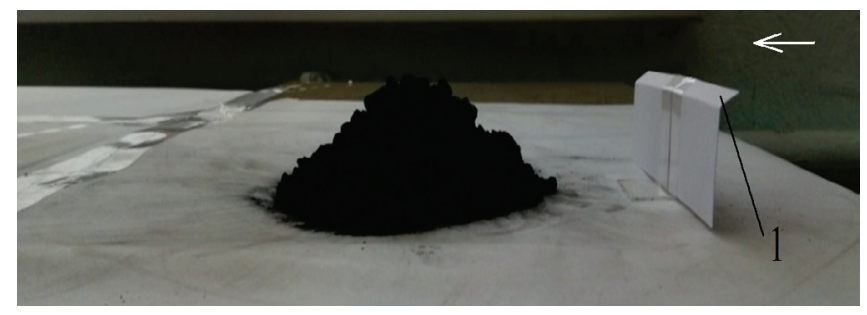

Fig. 5. Coal pile model: 1 - barrier (scenario \#3).

Application of barriers allows to reduce level of coal dust pollution near the coal pile and it is not possible to visualize the contamination zone near the pile. That is why 
contamination zones is not presented like it was for scenario \#1. Nonetheless the air pollution took place when barriers is used and detectors show dust concentration near the model of the coal pile. In Table 1 mean coal dust concentrations (PM2.5) at different points when the middle air speed was $9,8 \mathrm{~m} / \mathrm{s}$ are presented. Concentration of coal dust has been measured at the level which is equal to the height of the pile.

Table 1. Coal dust concentration behind the coal pile.

\begin{tabular}{|c|c|c|c|}
\hline \multirow{2}{*}{ Distance } & \multicolumn{3}{|c|}{ Concentration, $\mu \mathrm{g} / \mathrm{m}^{3}$} \\
\cline { 2 - 4 } & $\begin{array}{c}\text { Scenario \#1 } \\
\text { (no barrier) }\end{array}$ & Scenario \#2 & Scenario \# 3 \\
\hline $0.5 L$ & 239 & 28 & 12 \\
\hline$L$ & 122 & 11 & 5 \\
\hline $1.5 L$ & 33 & 5 & 3 \\
\hline
\end{tabular}

One can see from Table 1 that application of protection barriers having " $\Gamma$ " form allows to reduce air pollution behind the coal pile. Worthy of note that it is necessary to proceed laboratory experiments to obtain systematic results and make common conclusions. It is necessary to study impact of other different factors (dimensions of barriers and their position near the pile, etc.) on air pollution.

\section{Mathematical model}

To simulate coal dust dispersion from the coal pile when protection barriers are used CFD model has been developed. Governing equations are the following [3, 4, 6]:

$$
\begin{gathered}
\frac{\partial \omega}{\partial t}+\frac{\partial u \omega}{\partial x}+\frac{\partial v \omega}{\partial y}=\frac{1}{\operatorname{Re}}\left(\frac{\partial^{2} \omega}{\partial x^{2}}+\frac{\partial^{2} \omega}{\partial y^{2}}\right) \\
\frac{\partial^{2} \psi}{\partial x^{2}}+\frac{\partial^{2} \psi}{\partial y^{2}}=-\omega \\
\frac{\partial C}{\partial t}+\frac{\partial u C}{\partial x}+\frac{\partial(v-w) C}{\partial y}=\operatorname{div}(\mu \cdot \operatorname{grad} C)+\sum_{i=1}^{N} Q_{i}(t) \delta\left(x-x_{i}\right) \delta\left(y-y_{i}\right)
\end{gathered}
$$

where $\omega=\partial v / \partial x-\partial u / \partial y$ is vorticity, $\mathrm{s}^{-1} ; \operatorname{Re}=V_{0} L / v$ is Reynolds number, $L$ is a characteristic dimension in the computational region, $\mathrm{m} ; V_{0}$ is characteristic velocity in the computational region, $\mathrm{m} / \mathrm{s} ; \mathrm{v}$ is kinematic coefficient of viscosity, $\mathrm{m}^{2} / \mathrm{s} ; \psi$ is stream function, $\mathrm{m}^{2} / \mathrm{s} ; u=\partial \psi / \partial y, v=-\partial \psi / \partial x$ are components of wind velocity, $\mathrm{m} / \mathrm{s} ; C$ is coal dust concentration, $\mathrm{kg} / \mathrm{m}^{3} ; \mu_{x}, \mu_{y}$ are coefficients of turbulent diffusion, $\mathrm{m}^{2} / \mathrm{s} ; Q$ is coal dust emission rate, $\mathrm{kg} / \mathrm{s} ; \delta\left(x-x_{i}\right) \delta\left(y-y_{i}\right)$ are Dirac's delta functions; $\left(x_{i}, y_{i}\right)$ are Cartesian coordinates of coal dust emission point at the surface of the coal pile, $\mathrm{m} ; t$ is time, $\mathrm{s}$.

(1) and (2) are Navier-Stokes equations and (3) is equation of pollutant dispersion. Initial and boundary conditions for modeling equations (1) - (3) are discussed in [1, 4].

(1) and (2) are used to simulate wind flow in all computational region and near the surface of the coal pile to obtain information about so called "local speed". (3) is used to simulate coal dust concentration in the computational region.

Worthy of note, that coal dust emission rate depens on different factors, but the most importnt is the local wind speed near the coal pile surface. To calculate the coal dust 
emission rate from the coal pile surface, following empirical dependence is used [1]:

$$
Q=4.2\left(V-V_{t h}\right), \mu \mathrm{g} /\left(\mathrm{m}^{2} \mathrm{~s}\right),
$$

where $V$ is local wind speed, $\mathrm{m} / \mathrm{s}, V_{t h}$ is a threshold speed (speed when suspension of coal dust particles begins, $V_{t h}=1.58 \mathrm{~m} / \mathrm{s}$.).

For numerical integration of modeling equations (1) - (3) we used implicit difference schemes of splitting $[1,4]$. Worthy of note that for the problems of coal dust concentration prediction near the coal piles it is very important to simulate the geometrical form of piles or barriers. To describe geometrical form of different objects in computational region we used markers [4], so called "porosity technique".

\section{Results}

Coding of difference equations which discretized (1)-(3) has been performed and computer program "COAL" has been developed. Some results of CFD modeling are presented further which were obtained on the basis of developed model. This results show the possibility of developed model to simulate coal dust concentration when barriers having different geometrical form are used.

Figures 6,7 show results of computer simulation of scenario \#2 and scenario \#3, i.e. scenarios which have been studied during laboratory experiments.

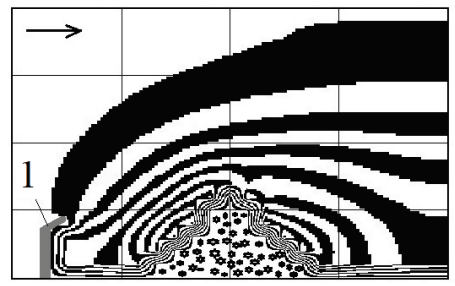

Fig. 6. Coal dust concentration near the coal pile: 1 - barrier (scenario \#2).

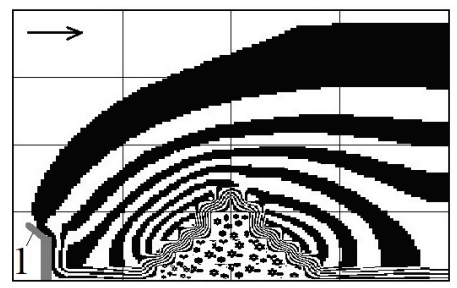

Fig. 7. Coal dust concentration near the coal pile: 1 - barrier (scenario \#3).

In Figures 8, 9 computed coal dust concentrations near the coal piles with "T" form barrier and with two barriers having different form are presented.

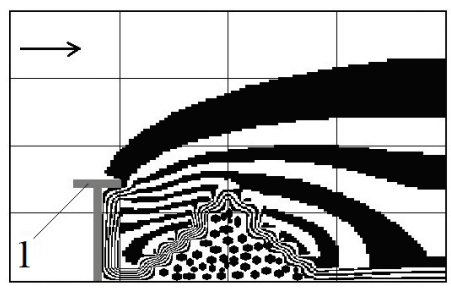

Fig. 8. Coal dust concentration near the coal pile: 1 - barrier having " $T$ " form. 


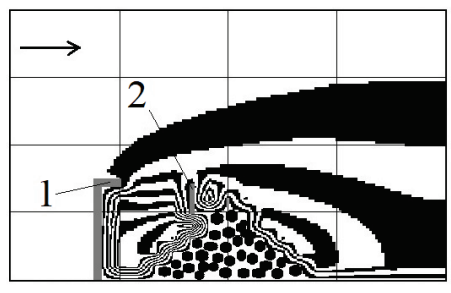

Fig. 9. Coal dust concentration near the coal pile: 1 - barrier having " $\Gamma$ " form; 2 -vertical barrier.

The results show that developed CFD model allows to take into account geometrical form of coal pile, geometrical form of protection barriers that is very important in this field of study.

Worthy of note that computational time was $15 \mathrm{~s}$ for one scenario. Such quick computing model will be usefull in case when different scenarios are considered and the most efficient scenario must be selected.

\section{Conclusions}

We present some results of laboratory study of barriers impact on air pollution near the coal pile. The obtained results show that barriers having " $\Gamma$ " form can improve environment conditions near coal pile. Also, CFD model to simulate air pollution near coal pile was proposed. To model wind flow over the coal pile Navier-Stokes equations written in variables "vorticity - stream function" were used. The model allows to obtain quickly numerical results about air pollution. Developed CFD model allows to take into account the main factors which influence the contamination zones formation, namely: coal pile geometrical form, meteo situation parameters, barriers geometrical form and their position near the coal pile.

\section{References}

1. Biliaiev, M.M., Kozachyna, V.A., Oladipo, M.O. (2019). Numerical analysis of atmosphere pollution from coal trains. East European Science Journal, 3(43), 10-15

2. Kolesnik, V.Ye., Holovina, L.A., Bohutskaia, V.V. (2006). Mathematical modeling of enterprise dust dispersion in atmosphere. Collection of Research Papers of the National Mining University, 26, 20-130

3. Marchuk, G.I. (1982). Mathematical modeling in environmental problems. Moskva: Nauka

4. Zgurovskii, M.Z., Skopetskii, V.V., Khrusch, V.K., Biliaiev, M.M. (1997). Numerical modeling of pollutant dispersion in environment. Kyiv: Naukova dumka

5. J. T. Alvarez, I. D. Alvarez, S. T. Lougedo, WIT Transactions on Ecology and the Environment, 116 (2008)

6. M. Biliaiev, NATO Science for Peace and Security, Series C: Envir. Sec. (2011)

7. C.-W. Park, S.-J. Lee, Atmospheric Environment, 36 (2002)

8. Mrinal, K. Ghose, Journal of Scientific and Industrial Research, 63 (2004)

9. W.R. Reed, Significant Dust Dispersion Models for Mining Operations (DHHS (NIOSH) Publication, 2005)

10. I. Diego, A. Pelegry, S. Torno, J. Torano, M. Menendez, Applied Mathematical Modeling, 33 (2009)

11. C. Song, L. Peng, J. Cao, L. Mu, H. Bai, X. Liu, (2014), Aerosol and Air Quality Research, 14 (2013) 